\title{
O MODELO ORGANIZACIONAL DA UNIDADE DE SAÚDE FAMILIAR DE PORTUGAL: UMA ANÁLISE DOS DISCURSOS OFICIAIS
}

\author{
THE ORGANIZATIONAL MODEL OF FAMILY HEALTH UNIT IN PORTUGAL: AN ANALYSIS OF THE \\ OFFICIAL DISCOURSE
}

\section{EL MODELO ORGANIZACIONAL DE LA UNIDAD DE SALUD FAMILIAR DE PORTUGAL: UN ANÁLISIS DE LOS DISCURSOS OFICIALES}

\author{
Josefa Lusitânia de Jesus Borges ${ }^{1}$ \\ Maria Helena Santana Cruz ${ }^{2}$ \\ Maria Amélia da Costa Lopes ${ }^{3}$
}

Resumo O objetivo deste artigo é refletir sobre as transformações do trabalho, as demandas de qualificação e de novas competências no âmbito da política de saúde primária, atribuindo especial destaque aos impactos no trabalho dos médicos nas unidades de saúde familiar em Portugal. A investigação de caráter qualitativo realizou-se por meio da consulta a fontes documentais: decretos, leis, planos de ação e relatórios referentes às políticas e à estrutura organizacional nas unidades de saúde, adotando-se a análise de conteúdo para o tratamento dos dados. Preconiza-se que o comprometimento com os processos de requalificação enseja novos movimentos instituintes, fortalecedores da (re)construção da identidade médica, não apenas compreendida como individuação/identificação, mas constituída como um processo contínuo vinculado à identidade pessoal, possibilitando a construção, desconstrução e a reconstrução de algo que permite dar sentido ao trabalho realizado. Para o trabalho em saúde, valoriza-se um novo perfil profissional dotado de elevada qualificação, integrando, de forma inseparável, teoria, saberes técnicos, práticos e sociais. A 'prestação do serviço' e a 'assistência em saúde' têm uma dimensão subjetiva e individual, mas, ao mesmo tempo, têm expressão em grupos e em populações, assim como são orientadas por valores culturais e pelos padrões clínicos reconhecidos pela ciência.

Palavras-chave saúde; trabalho; qualificação.
Abstract The aim of this paper is to discuss the transformations that have taken place in work, the demands of training, and new skills in the primary health policy, with particular emphasis on the impacts on the work of physicians in the family health units in Portugal. The qualitative survey was carried out by querying documentary sources: Decrees, laws, action plans, and reports on the policies and organizational structure in health facilities, adopting content analysis to process data. It recommends that the commitment to the renewal process entails new instituting movements, which empower the (re)construction of the medical identity, understood not only as individuation/identification, rather constituted as an ongoing process linked to personal identity, enabling the construction, deconstruction, and reconstruction of something that gives meaning to the work done. For work in health, we value a new professional profile provided with highly qualified, integrating, inseparably, theory, technical, practical, and social knowledge. 'Service provision' and 'health care' have a subjective and individual dimension; however, at the same time they are expressed in groups and populations, and are guided by cultural values and clinical standards recognized by science.

Keywords Health; work; training. 


\section{Introdução}

Este artigo 4 é parte de um estudo maior que objetivou analisar a construção das identidades profissionais dos médicos que atuam em Cuidados em Saúde Primária (CSP) no Brasil e em Portugal. Os dados aqui apresentados tratam, de forma particular, das unidades de saúde familiar (USFs) em Portugal, tendo em vista as seguintes configurações: as diretrizes organizacionais postas no contexto do trabalho e os novos requisitos de qualificação.

\section{Política de Atenção Primária: o lugar das unidades de saúde familiar em Portugal}

A política de saúde nas sociedades ocidentais passa por transformações constantes, tanto em nível macro como também nas singularidades locais. Nos mais variados contextos observam-se a criação de estratégias e novos modelos de organização que sofrem influências dos campos político, econômico e social. No cenário atual, a saúde primária vem ganhando força como estratégia estruturante dos sistemas de saúde.

Cabe esclarecer que a atenção primária, historicamente, surgiu na Inglaterra, no ano de 1920, com o Relatório Dawnson (1964), o qual apontava críticas ao modelo flexeneriano, baseado na visão predominantemente biologicista. Esse mesmo relatório mencionava, também, uma preocupação com o alto custo econômico da atenção médica, até então preponderante, e sua baixa resolutividade. Por isso, reorganizou-se o sistema de saúde, de modo que a atenção primária estivesse estruturada a partir da ideia de centros regionais de saúde. Os serviços assistenciais de saúde deveriam ser resolvidos inicialmente pelo profissional médico com formação em clínica geral. O modelo preconizava primeiramente a regionalização dos centros de saúde com base na população e nas necessidades locais, destacando a hierarquização da atenção. Outra particularidade refere-se à integralidade, fundamentada na ideia de articulação e indissociabilidade entre as ações preventivas e curativas.

Em várias partes do mundo, evidenciam-se processos de mudança no tocante a essa questão, isto porque, em alguns países, as ações são focadas e estruturadas a partir de uma perspectiva de prestação de serviço de baixa qualidade. Em várias partes, registram-se experiências exitosas com impactos positivos nos indicadores de saúde, a exemplo do que vem ocorrendo no Serviço Nacional de Saúde (SNS) de Portugal. Destaca-se, ainda, o processo de reestruturação da política de saúde que ocorreu a partir do ano de 2005 em Portugal, denominada reforma dos CSP, a qual vem produzindo alterações significativas nos processos de trabalho. 
Interessa, para fins desta abordagem, identificar o lugar que a USF ocupa nesse cenário, sob o ponto de vista organizacional, e os princípios e as diretrizes que têm sustentado o modelo. Nessa direção, ressalta-se que foi criada a Missão para os Cuidados em Saúde Primária (MCSP), no âmbito do Ministério da Saúde de Portugal, que estruturou e conduziu a execução das principais mudanças concernentes à reestruturação em curso, no período de 2005 a 2010, o qual foi denominado de primeira fase.

A MCSP organizou-se em torno da ideia de regionalização da saúde, obedecendo a uma ordem geográfica, no sentido de compartilhar e possibilitar ganhos de saúde de forma abrangente, baseada no princípio da equidade. Foram criadas cinco regiões de saúde em Portugal, denominadas Administração Regional de Saúde (ARS), a saber: Administração Regional de Saúde do Norte, Administração Regional de Saúde do Centro, Administração Regional Lisboa e Vale do Tejo, Administração Regional de Saúde do Alentejo e Administração Regional de Saúde do Algrave, as quais englobam os Agrupamentos de Centro de Saúde (ACSs) sustentados no pressuposto da descentralização da gestão. Tais regiões englobam várias unidades funcionais que têm como objetivo garantir os cuidados primários de modo ampliado, complementar e articulado em uma dada região de saúde, formando, portanto, uma rede integrada de atenção à saúde.

Sob o ponto de vista organizacional, cada unidade está estruturada a partir de uma equipe multiprofissional (que possui autonomia técnica e autonomia organizacional e atua de modo cooperado entre si). A composição das equipes ocorre de forma voluntária, o que significa dizer que critérios como a afinidade entre os membros constitui um ponto forte de sua autonomia. Nas palavras de Souza et al., trata-se de uma "formação do tipo bottom-up (caráter participativo, ascendente, a partir dos profissionais no nível local das unidades de saúde)" (Souza et al., 2013, p. 192).

\section{As novas competências para o trabalho em saúde e a questão das identidades profissionais}

Compreende-se que esse conjunto de valores e normas traz implicações que repercutem nas identidades profissionais, sobretudo quando se considera que o trabalho em equipe requer, entre outras questões, um corpo de profissionais que desenvolva um sentido de pertinência, de identidade coletiva por meio de compartilhamentos comuns, que vão além das suas corporações nucleares. Tais aspectos são expressivos no campo do trabalho nas USFs. Sobre essa questão, Zarifian entende "que não se construirão nem se negociarão garantias coletivas sólidas se não forem sustendas por pertinências" (Zarifian, 2003, p. 112). 
O desafio torna-se maior na medida em que o trabalho em saúde é marcado pela heterogeneidade que compõe o seu corpo profissional. As técnicas, o conhecimento e a linguagem diferenciam-se e definem o lugar que cada ator ocupa no processo de trabalho; contudo, paradoxalmente, eles se complementam; e esse trabalho complementar é marcado por resistências e conflitos, mas pode vir a contribuir signficativamente para o desenvolvimento de uma consciência e de uma identidade.

Essa perspectiva oportuniza processos de socialização por meio da interação com outros significados e papéis, o que exige, necessariamente, um grupo de trabalhadores relativamente estáveis, significando, entre outras questões, também a necessidade de construção de um plano de carreira comum para as diferentes profissões integrantes das equipes que possibilite aos sujeitos realizarem escolhas. Podemos ressaltar a formação espontânea das equipes, como vem ocorrendo na experiência portuguesa na medida em que ela considera o nível de satisfação profissional, pessoal e de interação entre seus membros tanto quanto as oportunidades de progressão na carreira a partir da definição de méritos.

Nessa linha de reflexão, conforme Merhy (2007, p. 49), “o trabalho em saúde não pode ser globalmente capturado pela lógica do trabalho morto, expresso nos equipamentos e nos saberes tecnológicos estruturados (...)". Para o autor, nas intervenções em ato, operam-se encontros de subjetividades, significando um grau de liberdade por parte dos profissionais no sentido de escolher o modo de fazer essa produção. Tal análise desvincula a ideia do trabalho em saúde pautado unicamente pela estruturação dos equipamentos tecnológicos.

Em pesquisa realizada por Favoreto (2009), o autor destaca os obstáculos para a concretização da competência dialógica de médicos no âmbito dos serviços de Atenção Primária à Saúde (APS) e a importância de considerar a clínica como um campo de produção de saberes. Em concordância com o autor, entende-se que

a competência dialógica dos profissionais de saúde representaria a capacidade de entender e interpretar o significado e a importância das estórias, a habilidade para discernir e analisar os elementos inconscientes que podem estar refletidos nas formulações narrativas apresentadas pelos pacientes e a possibilidade de que os médicos direcionem suas ações a partir das perspectivas dos pacientes (Jones, 1997; Favoreto, 2006 apud Favoreto, 2009, p. 214).

Sob essa perspectiva, cabe sinalizar que as transformações que vêm ocorrendo no mundo do trabalho, particularmente no trabalho em saúde, possibilitam "recriar um vínculo entre competência e profissão" (Zarifian, 2003, p. 109). 
A concepção retro apresenta resistências e constitui elementos de disputas no interior das relações de saber-poder das equipes, na conformação da sua hierarquização. Isso significa ir de encontro aos processos de socialização vivenciados pelos sujeitos, no âmbito da formação, junto as suas entidades de classes que são estruturantes da identidade, ao tempo que significa "sair da lógica do posto de trabalho (...): fazer com que, de algum modo, o trabalho seja reabsorvido pelo indivíduo que o realiza. E isso que significa também a inclinação para o modelo de competência" (Zarifian, 2003, p. 76).

\section{Trajeto metodológico}

A metodologia empregada foi a pesquisa qualitativa por se considerar que ela fornece elementos que possibilitam maior compreensão do fenômeno no campo desta investigação. Foram consultadas diferentes fontes: decretos, leis, planos de ação referentes à política organizacional das USFs para se recuperar o modelo de qualificação e de trabalho no âmbito dessas unidades.

A seleção dos documentos baseou-se em critérios de representatividade e pertinência da relação com o objeto de investigação, para identificar os conteúdos dos discursos presentes nas diretrizes da política pública de saúde do país, referentes à estrutura organizacional e a sua relação com os requisitos de qualificação dos médicos especialistas em Medicina Geral e Familiar. Entendeu-se que essa articulação, apesar de não ser determinante da estruturação das representações dos atores, exerce importante mediação. $\mathrm{O}$ acesso aos documentos ocorreu por meio da página web do Ministério da Saúde de Portugal, possibilitando fazer uma leitura do material, prepará-los para a análise, a partir da clareza de que eles continham dados significativos sobre o objeto investigado.

A análise de conteúdo mostrou-se relevante para a codificação e compreensão dos modos como as identidades profissionais dos médicos são estruturadas em contextos particulares no conjunto das mudanças societárias (Dubar, 2003). A análise de conteúdo adotada no tratamento dos dados foi composta, conforme Moraes (1999), por cinco etapas: preparação das informações, uniterização, categorização, descrição e interpretação. Procurou-se destacar a relação entre as ideologias, as intenções, as estratégias presentes nas diretrizes organizacionais em nível macro e micro na relação que se processa no interior dos contextos empíricos. Compreende-se que "por detrás do discurso aparente geralmente simbólico e polissêmico esconde-se um sentido que convém desvendar" (Bardin, 1998, p. 14). 


\section{Preparação das informações}

A sistematização do corpus documental da pesquisa foi submetida à análise, e sua escolha realizada de acordo com o objetivo deste estudo. Procurou-se obedecer a regras de exaustividade, de representatividade, por meio de uma amostra documental exposta no Quadro 1:

Quadro 1

Documentos analisados

Decreto-lei n. 298, de 22 de agosto de 2007, que estabelece o regime jurídico da organização e do

funcionamento das USFs e o regime de incentivos a atribuir a todos os elementos que as constituem.

Missão para os Cuidados de Saúde Primários. Cuidados Continuados Integrados nos Cuidados de Saúde

Primários: Carteira de Serviços.

Cuidados de saúde primários. Agora mais do que nunca. O que está a mudar nos cuidados de saúde primários

em Portugal? Texto 1 da série A reforma de $A$ a $Z$.

Decreto-lei n. 177, de 4 de agosto de 2009. Estabelece o regime de carreira médica especial, bem como os

requisitos de habilitação profissional.

Nota Técnica n. 1/acss-poph/2011 - Tipologia de intervenção 3.6 qualificação dos profissionais da saúde.

Fonte: Dados produzidos pelas autoras com base nos documentos.

USFs: Unidades de saúde familiar

Cabe destacar o decreto-lei n. 177, de 4 de agosto de 2009, que trata da carreira médica única, em regime especial dentro da administração pública, a qual, embora esteja organizada por áreas de exercício profissional, é constituída por meio de deveres funcionais comuns para todos os médicos. É marcada, sobretudo, por etapas que contemplam a avaliação entre pares e o reconhecimento institucional, além de funcionar como um requisito ou um estímulo para a diferenciação profissional, conforme está posto no referido decreto (Portugal, 2009).

\section{Uniterização}

Para dar conta da transformação em unidades, utilizou-se o software QRSNvivo, por meio do recorte do material empírico orientado a partir das categorias, uma vez que ele é adequado às pesquisas qualitativas e permitiu a organização das categorias e seu cruzamento, facilitando assim a sua posterior interpretação e articulação com o arcabouço teórico. A unidade de análise ocorreu a 
partir de frases, por se entender que essas eram significativas e possuidoras de sentido. De acordo com Moraes (1999, p. 7), "as unidades podem ser tanto as palavras, frases, temas ou mesmo os documentos em sua forma integral".

\section{Categorização}

A partir do discurso oficial, foi eleita e codificada a dimensão do modelo organizacional da unidade de saúde familiar, a qual compreende as categorias ('estrutura organizacional', 'autonomia organizacional' e 'técnica', 'carreira', 'saber-poder') e as subcategorias ('relação ministério da saúde e entidade médica', 'relação médico/utente'); na dimensão qualificação foram incorporadas as categorias 'competência técnica' e 'competência social'.

As dimensões surgiram dos dados documentais analisados encontrando-se correspondência com as categorias teóricas, a partir da compreensão de que, no contexto de trabalho, quando inter-relacionadas, provocam mudanças nos sistemas simbólicos anteriores, alteram as regras e incidem sobre a constituição das identidades profissionais. É na interação com os contextos sociais, com as instituições e no percurso de suas trajetórias de vida que se constituem as identidades para si e as identidades para outro, esta última atribuída e intimamente relacionada ao espaço social e histórico, conforme esclarece Dubar (2005).

Procurou-se agrupá-las tendo em vista os objetivos da pesquisa e o material de análise. Melhor dizendo, algumas foram estabelecidas a priori, a partir do construto teórico, a exemplo das categorias 'carreira', 'saber-poder', 'competência técnica' e 'competência social' e outras como, 'estrutura organizacional', 'autonomia organizacional' e autonomia 'técnica' e as subcategorias 'relação ministério da saúde e entidade médica' e 'relação médico/utente' emergiram dos dados empíricos. Quanto ao critério de exclusividade, optou-se por não seguir o princípio da exclusividade das categorias por se entender que os mesmos enunciados, quando relacionadas a contextos diferentes, podem traduzir outros significados. Todavia, torna-se claro que a condição anteriormente mencionada, não elimina os critérios de fidedignidade.

\section{Apresentação e discussão dos dados}

Os dados referentes à dimensão do modelo organizacional das USFs fora estruturados a partir das categorias: 'estrutura organizacional', 'autonomia', 'carreira' e 'saber-poder'. A estrutura organizacional, no cenário da reforma dos CSP em Portugal, apresenta redes descentralizadas de equipes multiprofissionais, cada uma delas possuidora de uma 'missão específica'. 
A referida rede é constituída de unidades de cuidados na comunidade (UCCs), que têm como público alvo, em particular, as famílias, pessoas e grupos vulneráveis que necessitam de cuidados de saúde e apoio psicológico e social, além de estarem em situação de dependência física e funcional ou doença que requeira acompanhamento próximo. As unidades de recursos assistenciais partilhados (URAPs) centram-se na oferta de cuidados de saúde em diversas especialidades médicas, bem como em campos como a fisioterapia, a higiene oral, a psicologia, a nutrição, o serviço social, a terapia ocupacional, o diagnóstico radiológico e laboratorial; unidades de saúde pública (USPs) que funcionam como observatório de saúde da população. As unidades de saúde personalizadas (UCSPs) objetivam prestar cuidados personalizados de saúde a uma população inscrita em uma determinada área geográfica e as USF (Portugal, 2008).

$\mathrm{Na}$ estrutura de rede dos CSP foram criados os agrupamentos de centros de saúde (ACESs), agregando os centros de saúde que se organizam a partir de diretorias e conselhos executivos, os quais têm como propósito desenvolver competências locais para a gestão de recursos, por meio da Unidade de Apoio à Gestão (UAG), propiciando, assim, economia de escala, segundo consta nos documentos. Uma terceira linha diz respeito à denominada governação clínica e de saúde, a qual se sustenta na ideia de um sistema de pilotagem técnico-científica que envolve todos os profissionais de saúde, sob orientação dos conselhos clínicos de cada ACES e dos conselhos técnicos das unidades a eles relacionadas.

O conjunto de reformas estruturais e de gestão, baseadas em uma racionalidade organizacional, objetivam imprimir entre os profissionais um grau de comprometimento e envolvimento de modo que cada um se responsabilize e participe das transformações em curso. Evidencia-se que "o conceito essencial é o de trabalho em equipa. O elemento estrutural central é o de equipa" (Portugal, 2010, p. 1), de modo que haja uma complementaridade entre as ações. Significa dizer que novas competências e modos de ser e agir devem ser adquiridos por parte dos profissionais, evidenciando, portanto, que as competências coletivas, que se formam, segundo Zarifian (2011), nas próprias organizações do trabalho e exigem tanto complementaridade das ações quanto acordo entre seus membros, vêm ganhando força como elemento estruturador da organização do trabalho nesse âmbito. Neste ponto, foram incorporadas, contribuições da sociologia do trabalho, dos estudos sobre políticas em saúde, da formação e do currículo na área médica para penetrar a fundo na chamada 'pedagogia das competências', perspectiva esta seguida pelo setor da saúde na apropriação dos referenciais para a educação de seus trabalhadores.

A implementação das USFs baseia-se em um modelo de remuneração que recompensa as "aptidões e competências de cada profissional e pre- 
miando o desempenho individual e coletivo (...)" (Portugal, 2007a, p. 5.588) e objetiva a melhoria da qualidade dos cuidados primários em saúde, através de ganhos de eficiência e fortalecimento da eficácia. Tendência, de acordo com Machado (1996, p. 70), de “formação e hegemonização das organizações de saúde de cunho empresarial e a incorporação de mecanismos reguladores governamentais (...)". Nesse contexto, a ação profissional está prescrita no sentido de que novos valores, regras e saberes, a partir da introdução de mecanismos de mercado, de cunho empresarial e de regulação do estado, conforme descrito na afirmação retro, sejam introduzidos no cotidiano dos serviços de saúde.

Relativamente ao modelo das USFs, os discursos frisam que essas são unidades de prestação de cuidados de saúde, tanto do ponto de vista individual como familiar constituída por médicos de família, enfermeiros de família e pessoal administrativo. A categoria 'autonomia' é considerada, uma das características fundantes, na medida em que incorpora a dimensão organizacional, "que assenta na auto-organização funcional e técnica, visando o cumprimento do plano de acção" (Portugal, 2007b, p. 5.589) e a dimensão técnico-científica relativa ao uso correto das funções assumidas e à observância da autonomia e das características técnico-científicas inerentes a sua especialidade. A autonomia organizacional das USFs está delineada conforme Quadro 2:

Quadro 2

Autonomia organizacional da USF, Portugal, 2012
Cada USF elabora o seu regulamento interno e submete-o ao centro de saúde, que aprecia da conformidade
do mesmo com o plano de acção previsto no artigo $6 .^{\circ}$ do presente decreto-lei n. $297 / 2007$.
Os recursos financeiros são negociados anualmente entre a USF e o centro de saúde e constam da carta de
O centro de saúde coloca à disposição da USF os recursos financeiros constantes da carta de compromisso.
A forma de prestação de trabalho dos elementos da equipa multiprofissional consta do regulamento interno
cobertura assistencial e as modalidades de regime de trabalho previstas na lei.
O horário de trabalho a praticar por cada elemento da equipa multiprofissional deve resultar da articulação e
do acordo entre todos os profissionais.

Fonte: Portugal, 2007a

USF: Unidade de saúde familiar 
Acrescenta-se, também, que outras características concernentes às USFs dizem respeito à formação voluntária das equipes, a qual se dá pela formalização da candidatura no Ministério da Saúde, conforme despacho normativo n. 5/2011 do Gabinete do Secretário de Estado Adjunto e da Saúde, que regula o decreto-lei n. 298/2007. Destaca-se a contratualização de um plano anual de ações firmado entre a coordenação da USF e a diretoria executiva do ACES, englobando o compromisso assistencial daquele ano. A carteira básica de serviços e a carteira adicional de serviços com indicadores das metas a atingir são firmadas e formalizadas por carta de compromisso.

De acordo com o exposto no decreto-lei n. 298/2007, a carta de compromisso deve indicar (Quadro 3):

Quadro 3

\begin{tabular}{|c|c|}
\hline \multicolumn{2}{|l|}{ Carta de compromisso da USF, Portugal, 2012} \\
\hline A definição da oferta e a carteira básica de serviços. & Os horários de funcionamento da USF \\
\hline A definição do sistema de marcação, atendimento e orientação dos utentes. & A definição do sistema de renovação de prescrição. \\
\hline A definição do sistema de intersubstituição dos profissionais. & A articulação com as outras unidades funcionais do centro de saúde. \\
\hline A carteira de serviços adicionais, caso exista. & $\begin{array}{l}\text { A aceitação expressa das condições, dimensão e modos de colheita de } \\
\text { informação que permita às entidades autorizadas por despacho do Ministro } \\
\text { da Saúde avaliar os resultados da equipa e dos seus membros, em termos de } \\
\text { efectividade, eficiência, qualidade e equidade. }\end{array}$ \\
\hline
\end{tabular}

Fonte: Portugal, 2007a.

USF: Unidade de saúde familiar

Conforme consta nos documentos, "o compromisso assistencial varia em função das características da população abrangida, dos períodos de funcionamento e cobertura assistencial e das actividades da carteira adicional de serviços" (Portugal, 2007a, p. 5.589). Vale sinalizar que outro compromisso assumido pelas equipes das USFs refere-se à existência de uma carta de qualidade que objetiva firmar um comprometimento no que diz respeito à melhoria contínua da qualidade dos serviços prestados pelas equipes aos usuários; para tanto, desenvolvem estratégias a fim de dar cabo a esses objetivos. Temas como redução do tempo de espera para consulta, acessibilidade, compromisso com o direito do usuário de obter uma segunda opinião sobre a sua situação de saúde, entre outras questões, encontram-se presentes na carta de qualidade e passam a ser um compromisso formal para todos os membros das equipes. 
Quanto ao desenvolvimento organizacional das USFs, cabe informar que elas se constituem a partir dos modelos A, B e C, e a sua progressão resulta do grau de autonomia organizacional, do modelo de financiamento e da diferenciação do modelo retributivo e de incentivo, conforme o decreto-lei n. 298/2007. Segundo análise técnica do próprio Ministério da Saúde, o modelo retributivo é uma inovação na administração pública portuguesa e consiste em associar

o vencimento dos profissionais aos resultados do desempenho da equipa multiprofissional reforçando nas equipas o seu compromisso com os objetivos. Estimula a combinação e partilha de competências e o aperfeiçoamento contínuo de processos e de procedimentos de modo a otimizaros contributos de cada um para os bons resultados de toda a equipa. Visa obter efeitos que equilibrados em múltiplas dimensões daqualidade, da efetividade e da eficiência (Portugal, 2012, p. 2)

Em razão do grau da autonomia organizacional, funcional e técnica, tanto quanto da intrínseca relação entre os vencimentos profissionais aliados aos resultados do desempenho da equipe multiprofissional presente na configuração das USF, entende-se que cabe aos trabalhadores a responsabilidade e o controle sobre suas próprias atividades.

O modelo A é concebido como fase de aprendizagem, sobretudo no que tange ao trabalho em equipe; refere-se a grupos em que o trabalho ainda é fortemente marcado pelo isolamento e a individualidade, no qual não existe qualquer experiência de desempenho de avaliação técnico-científica. Essa fase também é considerada a primeira experiência para o desenvolvimento de práticas de contratualização. Observa-se que o modelo B é concebido e particularmente indicado para os grupos que já progrediram no trabalho em equipe de saúde familiar e que se consideram preparados para um nível de contratualização mais exigente. Já o modelo C tem como característica principal a existência de um contrato-programa, sendo que pode ser constituído tanto por equipes do setor público, cooperativo ou social. Está classificado como um modelo experimental de caráter complementar a ser regulado por regras próprias, específicas. Em Portugal, de acordo com dados do ano de 2012, existem 177 USFs no modelo A e 150 no modelo B, conforme dados disponibilizados no site do Ministério da Saúde em julho de 2012 (Portugal, 2012).

O caráter pedagógico do trabalho em equipe requer cada vez mais um nível de comprometimento e coesão dos profissionais requisitados pela organização. Tais profissionais devem se qualificar e adquirir habilidades que são inerentes ao trabalho em saúde familiar. É amplamente valorizado o estabelecimento de vínculos com a comunidade, apreensão da cultura local, novas técnicas de gestão, o que significa práticas intercambiadas pela constituição de um novo saber-poder, permeadas pela necessidade de afirmação 
da identidade médica. A estrutura da USF contempla o coordenador de equipe, o conselho técnico e o conselho geral. É possível observar as atribuições delineadas tanto para o conselho geral como para o conselho técnico no Quadro 4.

\section{Quadro 4}

\begin{tabular}{|l|l|}
\hline \multicolumn{2}{|c|}{ Atribuições do Conselho Geral e do Conselho Técnico da USF, Portugal, 2012 } \\
\hline \multicolumn{1}{|c|}{ Conseral } & \multicolumn{1}{c|}{ Conselho técnico } \\
\hline $\begin{array}{l}\text { Aprovar o regulamento interno, a carta da qualidade, o plano de acção, o } \\
\text { relatório de actividades e o regulamento de distribuição dos incentivos } \\
\text { institucionais. }\end{array}$ & $\begin{array}{l}\text { Compete ao conselho técnico a orientação necessária à observância das } \\
\text { normas técnicas emitidas pelas entidades competentes e a promoção de } \\
\text { procedimentos que garantam a melhoria contínua da qualidade dos cuidados } \\
\text { de saúde, tendo por referência a carta da qualidade. }\end{array}$ \\
$\begin{array}{l}\text { Aprovar a proposta da carta de compromisso. } \\
\begin{array}{l}\text { Zelar pelo cumprimento do regulamento interno, da carta de qualidade e } \\
\text { do plano de acção. }\end{array}\end{array}$ & $\begin{array}{l}\text { Avaliar o grau de satisfação dos utentes da USF e dos profissionais da equipa. } \\
\text { Propor a nomeação do novo coordenador. }\end{array}$ \\
$\begin{array}{l}\text { Aprovar a substituição de qualquer elemento da equipa multiprofissional. } \\
\text { Pronunciar-se sobre os instrumentos de articulação, gestão e controlo dos } \\
\text { recursos afectos e disponibilizados à USF. }\end{array}$ & $\begin{array}{l}\text { Organizar e supervisionar as actividades de formação contínua e de } \\
\text { investigação. }\end{array}$ \\
\hline
\end{tabular}

Fonte: Portugal, 2007a.

USF: Unidade de saúde familiar

No que tange ao conselho geral, é constituído por todos os membros da equipe multiprofissional. Cada membro da equipe responsabiliza-se por cumprir as obrigações contratualizadas a partir do seu núcleo profissional, considerando as especificidades do trabalho em saúde e os elementos fundamentais para uma atenção de qualidade.

\section{Carreira}

Outra categoria analisada nesta investigação refere-se à 'carreira'. Com base no pensamento de Hughes (1958), as profissões devem ser compreendidas tanto como carreira quanto como um meio de socialização, possibilitando o compartilhamento de visões de mundo, a exemplo da linguagem, das regras, dos códigos e valores. A socialização profissional é definida por Hughes (1958) a partir de três tipos de mecanismo. O primeiro refere-se à cultura profissional em confronto com a cultura leiga. Para o autor, “as relações entre a 
profissão médica e a cultura médica leiga têm variado muito do grau ideal em toda parte do mundo, mas a maioria da população aceita as premissas básicas anteriores (...)" (Hughes, 1958, p. 117). Já o segundo mecanismo concerne à dualidade existente entre aquilo que é posto como o ideal, o modo como a profissão é representada simbolicamente e a realidade, ou seja, pela luta para manter o controle. No processo de socialização ocorre a 'escolha de papéis', intercâmbios com outros significados. O terceiro mecanismo diz respeito à composição 'de um grupo de referência', à tomada de consciência de suas capacidades, à oportunidade de uma carreira futura.

No que concerne à categoria carreira, o discurso da política governamental portuguesa revela que as diretrizes da carreira profissional médica sustentam-se na progressão profissional e na diferenciação técnico-científica, possibilitando a mobilidade interinstitucional, de modo comum a todos os médicos que atuam no SNS, sejam aqueles vinculados às entidades públicas empresariais (EPE) ou às parcerias público-privadas (PPP). Estas não podem subverter a autonomia de gestão, tanto do setor empresarial do estado quanto das PPPs. A organização e valorização dos recursos humanos e o reconhecimento mútuo da qualificação podem ser observados no Quadro 5:

Quadro 5

\begin{tabular}{|c|c|c|}
\hline \multicolumn{3}{|c|}{ Carreira médica em Portugal, 2012} \\
\hline Qualificação médica & Aquisição de graus & Categorias \\
\hline Especialista & $\begin{array}{l}\text { O grau de especialista adquire-se com a obtenção } \\
\text { de títulos de especialista após a conclusão com o } \\
\text { aproveitamento do internato. }\end{array}$ & $\begin{array}{l}\text { Assistente } \\
\text { Assistente graduado } \\
\text { Assistente graduado sênior }\end{array}$ \\
\hline Consultor & $\begin{array}{l}\text { O grau de consultor adquire-se após habilitação } \\
\text { efectuada por procedimento concursal de provas } \\
\text { públicas, que tenha por base, cumulativamente: } \\
\text { avaliação curricular; prova de verificação de } \\
\text { aprofundamento de competências; exercício } \\
\text { efectivo, durante cinco anos, de funções com o } \\
\text { grau de especialista. }\end{array}$ & $\begin{array}{l}\text { para a admissão à categoria de assistente, é } \\
\text { exigido o grau de especialista; } \\
\text { para a admissão à categoria de assistente } \\
\text { graduado, é exigido o grau de consultor; } \\
\text { para a admissão à categoria de assistente } \\
\text { graduado sênior é exigida a duração mínima de } \\
\text { três anos de exercício efectivo com a categoria de } \\
\text { assistente graduado. }\end{array}$ \\
\hline
\end{tabular}

Fonte: Portugal, 2009. 
Os atributos de qualificação e de títulos de habilitação profissional são validados e sujeitos a inserção por processo concursal. Portanto, um dos requisitos para a incorporação do profissional médico como um dos membros das USFs é possuir especialidade em Medicina Geral e Familiar, o que denota uma tendência para a construção de um saber específico, de uma identidade técnico-profisssional.

Apreende-se, com base no arcabouço teórico, que no processo de socialização é necessário considerar a relação entre o trabalho, a carreira e suas possibilidades de escolha. A carreira deve ser compreendida como uma sucessão de fases que se diferenciam em tempo de mudanças.

Um dos aspectos da carreira é que as transformações são acompanhadas de ansiedades, pois elas implicam a necessidade de "mudança de um tipo de atividade para outra e implica o perigo de perder a habilidade; é também uma mudança de um tipo de responsabilidade para outro, de um papel para outro" (Hughes, 1958, p. 129), o que significa dizer que esse conjunto de transformações em curso realizadas no interior da gestão do trabalho em saúde na realidade estudada não só pressupõe modificações no processo organizacional e no processo de trabalho, mas também nas representações desses atores frente à necessidade de conciliar novos e antigos papéis.

\section{Saber-poder}

Na categoria 'saber-poder' revelam-se enunciados que informam a dinâmica da estrutura hierárquica das USFs. Os dados anunciam que o coordenador da equipe é o médico, o qual já deve ser designado desde o momento da candidatura. Resguardando a autonomia técnica dos médicos de família e dos enfermeiros de família, a equipe multiprofissional desenvolve suas atividades sob a orientação e o comando do coordenador. Em que pese a existência de um discurso direcionado para o trabalho em equipe multiprofissional, observa-se a permanência de uma estrutura hierárquica orientada pelo saber médico, denotando, assim, um modelo de estrutura verticalizada do trabalho em equipe, na qual, contraditoriamente, se mantém a hierarquização das funções.

No que concerne à subcategoria, 'relação entre o Ministério da Saúde e entidades médicas' , a formulação e tomada de decisões relativas à carreira médica, os documentos informam que foram ouvidas tanto as organizações sindicais quanto a ordem dos médicos. Tal escuta está formalmente documentada como resultante de um determinado momento histórico, de uma conjuntura particular, política e econômica favorável que possibilitou um diálogo mais aproximado e a construção de alianças entre as referidas entidades e o governo português. Neste ponto, merece destaque a Revolução dos Cravos, 5 de 25 de abril de 1974, para a implantação do plano especial de carreira médica, com destaque para 
o modelo que contempla a ascensão por grau no decorrer dos tempos, aliado ao reconhecimento da Medicina Geral e Familiar como uma especialidade.

Para Machado (1996), Freidson (2009) e Foucault (2010), a aliança entre a medicina moderna e o Estado é histórica, portanto diversa, e pode ocorrer tanto com a elite, compradores dos seus serviços, quanto com o próprio Estado, "que concede e garante, através de sistemas legais, a exclusividade do exercício, ou seja, o monopólio -, e selou esse sucesso reconhecido em todo o mundo" (Machado, 1996, p. 32). A discussão acerca do trabalho médico, seu processo de qualificação e a construção identitária passa, necessariamente, pelo debate sobre a constituição do saber, a racionalidade científica que baliza sua práticas e, em especial, sobre a sua relação com a medicina moderna e desta com o Estado.

Quanto à subcategoria 'relação entre médicos e utentes' no âmbito do trabalho nas USFs, a lógica argumentativa do discurso aponta para uma relação de partilhamento, participação e corresponsabilidade entre os profissionais e a população usuária do serviço. Evidencia-se uma tendência de aproximação na medida em que busca "assegurar a realização de reuniões com a população abrangida pela USF ou com os seus representantes, no sentido de dar previamente a conhecer o plano de acção e o relatório de actividades" (Portugal, 2007b, p. 5.591). Tal tendência nas estruturas funcionais, denominadas gabinete do cidadão, presentes em todas as unidades e serviços de saúde contempla, entre essas e outras estratégias, o Livro de Reclamações. Este é um instrumento presente nos organismos e instituições públicas e privadas do país, de forma física ou virtual. Na cultura da sociedade portuguesa, constitui um mecanismo sério que confere ao cidadão o direito "de tomar parte na decisão dos assuntos públicos e de apresentar, perante órgãos de soberania ou quaisquer outras autoridades, reclamações ou queixas para defesa dos seus direitos" (Portugal, 2009, p. s/n).

As questões do sigilo profissional e éticas reforçam a necessidade do esclarecimento, por parte dos profissionais, sobre os cuidados, no sentido de assegurar "a efectividade do consentimento informado" (Portugal, 2009, p. 5.049). É importante salientar que os aspectos como confiança e vínculo são estruturantes nas relações entre cuidador e cuidado, pois o trabalho em saúde é de caráter relacional.

\section{Qualificação, competência técnica e competência social}

A discussão acerca do trabalho em saúde e a construção da identidade profissional médica passa, necessariamente, pelo debate do modo como está configurada a relação entre qualificação, instituição e trabalho nas singularidades dos contextos locais. A política de qualificação é um espaço privilegiado de experiência relacional, de verbalização, de mediação entre o si anterior, 
cons-truído em outros processos de socialização, e o novo si próprio (Dubar, 2005), entre o processo de formação, o processo de trabalho em saúde e a socialização, possibilitando uma passagem entre os saberes anteriores e os novos. Na dimensão qualificação, foram incorporadas as subcategorias 'competência técnica' e 'competência social'.

Verifica-se, nos enunciados da dimensão qualificação, que "um dos factores críticos do sucesso do SNS é o da qualificação e do desenvolvimento técnico-científico dos seus profissionais, designadamente dos médicos" (Portugal, 2009, p. 5.047). Evidencia-se o entrelaçamento entre o êxito do sistema de saúde articulado e o da capacidade de desenvolvimento dos conhecimentos técnicos, denotando, portanto, a valorização da questão científica dos médicos. Por outro lado, a formação "é uma das prioridades estratégicas da reforma dos cuidados em saúde primária em Portugal" (Portugal, 2011 , p. 1). As ações de formação se estendem aos demais trabalhadores da USF, a exemplo dos enfermeiros de família e dos secretários clínicos, ou seja, há também uma ênfase na formação/qualificação da equipe. Um dos seus objetivos consiste em "promover uma nova visão e atitudes quanto aos modos de organização, de prestação de cuidados e de mediação e valorização dos resultados em CSP, em Portugal" (Portugal, 2011, p. 1).

De acordo com Zarifian (2003, p. 117), “a competência não substitui a profissão, mas lhe dá um novo significado. É em torno desse novo significado que, provavelmente, as pertinências e as identidades poderão redefinir-se". Tal modelo tem na cooperação, na ajuda mútua nas atividades dos profissionais, na comunicação e no agir compartilhado a sua fundamentação. Portanto, deduz-se, a partir da pesquisa, que existe uma tendência para o modelo de competência na organização dos CSPs Portugal, ainda que esse não se apresente de forma explícita nos discursos oficiais.

As novas formas de organização do trabalho em saúde sinalizam também para outra tendência que prima pela "centralidade do ator que se forma" (Canário, 2003, p. 10) crescente no contexto de atuação da realidade pesquisada. Um dos requisitos postos para introduzir essas mudanças nas organizações e instituições de saúde é o entrelaçamento entre formação e trabalho. Conforme frisa Canário,

o papel e a importância cada vez mais decisivos, atribuídos ao factor humano na vida das organizações do trabalho tornam dificilmente dissociáveis as capacidades individuais das capacidades de mudança colectiva das organizações e de sua cultura (...) (Canário, 2003, p. 10).

A perspectiva explicitada pelo autor reafirma, portanto, uma tendência na experiência portuguesa entre o contexto, as situações de trabalho e os processos de formação. 
Os elementos norteadores caminham no sentido de fomentar novas habilidades, competências técnicas e sociais junto aos profissionais envolvidos, especificamente, direcionadas para a obtenção de ganhos no que tange aos cuidados em saúde primária. No tocante às categorias 'competência técnica' e 'competência social' elas encontram-se delineadas conforme se observa no Quadro 6:

\section{Quadro 6}

\begin{tabular}{|c|c|}
\hline Competência técnica & Competência social \\
\hline $\begin{array}{l}\text { Competências de governação clínica e de saúde (inclui métodos e } \\
\text { instrumentos de melhoria contínua da qualidade) a vários níveis } \\
\text { (institucional; interunidades; equipa; individual. }\end{array}$ & $\begin{array}{l}\text { Equipas multiprofissionais motivadas, portadoras de uma cultura de } \\
\text { responsabilização partilhada e com práticas cimentadas na reflexão crítica e } \\
\text { na confiança recíproca. }\end{array}$ \\
\hline $\begin{array}{l}\text { Competências de gestão de recursos (pessoas, instalações, equipamentos, } \\
\text { consumíveis, energéticos, de informação e financeiros). }\end{array}$ & $\begin{array}{l}\text { A equipa multiprofissional deve potenciar as aptidões e competências de } \\
\text { cada grupo profissional e contribuir para o estabelecimento de uma relação } \\
\text { interpessoal e profissional estável. }\end{array}$ \\
\hline $\begin{array}{l}\text { Competências e destreza no uso apropriado das tecnologias de informação } \\
\text { e registros clínicos e técnicos correctos, sem comprometer a qualidade da } \\
\text { comunicação e a atenção para com os utentes. }\end{array}$ & $\begin{array}{l}\text { Conciliação, que assegura a prestação de cuidados de saúde personalizados, } \\
\text { sem descurar os objectivos de eficiência e qualidade. }\end{array}$ \\
\hline $\begin{array}{l}\text { Competências de contratualização nos elementos que integrem } \\
\text { departamentos, órgãos ou equipas com esta missão em nível nacional, } \\
\text { regional e local. }\end{array}$ & $\begin{array}{l}\text { Cooperação, que se exige de todos os elementos da equipa para a } \\
\text { concretização dos objectivos da acessibilidade, da globalidade e da } \\
\text { continuidade dos cuidados de saúde. } \\
\text { Solidariedade, que assume cada elemento da equipa ao garantir o } \\
\text { cumprimento das obrigações dos demais elementos de cada grupo } \\
\text { profissional. }\end{array}$ \\
\hline
\end{tabular}

Fonte: Portugal, 2007a.

USFs: Unidades de saúde familiar

Os argumentos presentes na lógica discursiva indicam que a política de saúde primária, e consequentemente as USFs, vivenciam um período de transição e transformação, uma tendência para a construção, conforme sinaliza Dubar (2003), “de formas de identidades profissionais no seio das quais a formação é tão importante quanto o trabalho, os saberes incorporados são tão estruturantes como as posições de ator" (Dubar, 2003, p. 46). A incorporação de novas formas de identidades profissionais, na singularidade do contexto em questão, afirma-se por meio da união dos conteúdos relativos a situações de trabalho ao discurso dos profissionais articuladas à sua trajetória biográfica. 
Em razão de o modelo organizacional valorizar a autonomia, as prioridades de educação permanente são definidas pelas equipes das USFs no seu plano de ação elaborado pela equipe e depois enviado para a ACS, para aceitação. Os conteúdos desenvolvidos são variados, abordam desde questões clínicas, técnico-científicas, até mediação de conflitos como também no campo das relações humanas, entre outros.

Também há registro de ofertas de cursos para todos os profissionais das equipes gestados e ministrados pela Associação Nacional das Unidades de Saúde Familiar (USF-AN) e financiados pelo governo ou organismos internacionais e, por isso mesmo, gratuitos, como também são ofertados cursos financiados pelos próprios trabalhadores, a depender de seus interesses e necessidades.

Nos processos de formação, são valorizados saberes do campo da administração, planejamento, da economia em saúde, informática, entre outros que tenham aplicabilidade prática e relação com o saber-fazer dos profissionais no cotidiano dos serviços. Portanto, esses saberes ampliam-se para além daqueles que são adquiridos na formação inicial desse conjunto de trabalhadores. Isso significa, contudo, que tal perspectiva mostra-se complexa frente à necessidade imposta de incorporação de novas competências no contexto do trabalho.

\section{Considerações finais}

Em conformidade com os discursos sobre o processo de trabalho, constatase que a competência para o trabalho em saúde é compreendida dentro de uma lógica em que os aspectos da subjetividade e das singularidades individuais são expressos e reconhecidos. Evidencia-se não somente a dimensão individual ou a sujeição, a adequação do trabalhador ao estabelecido, às regras, mas também a incorporação por parte dele da ideia de uma responsabilidade pessoal e coletiva.

As instituições públicas de saúde e a dimensão do modelo organizacional e de qualificação para o trabalho assumem, nessa perspectiva, uma real importância na condição de variável produtora de competências e modos de ser e agir, e constitui-se como um atributo significativo para a construção do sentimento de pertencimento.

Vem ocorrendo, no âmbito das políticas de saúde e nas práticas profissionais em saúde primária em Portugal, tanto a valorização do trabalho em equipe quanto a demanda por novas competências. Suscitam-se hipóteses de que tanto as políticas como as práticas desenvolvidas combinam a racionalidade técnica e os saberes sociais. Os novos requisitos de qualificação contribuem para transformações identitárias, pois parte do pressuposto de 
que a identidade é construída na realidade, nas experiências profissionais, num processo de permanente mudança.

\section{Colaboradores}

Josefa Lusitânia de Jesus Borges concebeu e redigiu o artigo. Maria Helena Santana Cruz orientou e participou da redação final do artigo. Maria Amélia da Costa Lopes contribuiu na orientação e revisão do artigo. Os autores declaram que não há conflitos de interesse.

Resumen El objetivo de este artículo es reflexionar sobre las transformaciones del trabajo, las demandas de calificación y de nuevas competencias en el ámbito de la política de salud primaria, atribuyendo especial destaque a los impactos en el trabajo de los médicos en las unidades de salud familiar en Portugal. La investigación de carácter cualitativo se realizó por medio de la consulta a fuentes documentales: decretos, leyes, planes de acción e informes referentes a las políticas y a la estructura organizacional en las unidades de salud, adoptándose el análisis de contenido para el tratamiento de los datos. Se preconiza que el comportamiento con los procesos de recalificación entraña nuevos movimientos instituidores, fortalecedores de la (re)construcción de la identidad médica, no solo comprendida como individualidad/identificación, sino constituida como un proceso continuo vinculado a la identidad personal, permitiendo la construcción, desconstrucción y la reconstrucción de algo que permite dar sentido al trabajo realizado. Para el trabajo en salud, se valoriza un nuevo perfil profesional dotado de elevada calificación, integrando, en forma inseparable, teoría, saberes técnicos, prácticos y sociales. La 'prestación del servicio' y la 'asistencia en salud' tienen una dimensión subjetiva e individual, pero, al mismo tiempo, tienen expresión en grupos y en poblaciones, así como están orientadas por valores culturales y por estándares clínicos reconocidos por la ciencia.

Palabras clave salud; trabajo; calificación. 


\section{Notas}

1 Universidade Federal de Sergipe, Departamento de Serviço Social, Aracaju, Sergipe, Brasil.

$<$ lusitaniaborges@hotmail.com>

Correspondência: Rua Percílio Costa Andrade, n. 175, apartamento 901, 13 de Julho, CEP 49020-600, Aracaju, Sergipe, Brasil.

2 Universidade Federal de Sergipe, Centro de Ciências Sociais Aplicadas, Aracaju, Sergipe, Brasil.

$<$ helenacruz@uol.com.br>

3 Universidade do Porto, Faculdade de Psicologia e Ciências da Educação, Porto, Portugal.

<amelia@fpce.up.pt>

$4 \mathrm{O}$ presente artigo faz parte da tese de doutorado Representações do trabalho médico em saúde da família: algumas considerações sobre Brasil e Portugal, de autoria de Josefa Lusitânia de J. Borges, e é resultante, mais especificamente, dos trabalhos desenvolvidos no doutorado sanduíche na Universidade do Porto, em 2012. A pesquisa foi financiada com bolsa de estudo (processo n. 9850-11-2), concedida pela Coordenação de Aperfeiçoamento de Pessoal de Nível Superior (Capes). A pesquisa foi aprovada pelo Comitê de Ética da Universidade Federal de Sergipe.

5 Movimento em Portugal que derrubou a ditadura salazarista, inspirada no nazifascismo, restaurando a democracia no país e resultando em ganhos no campo político, econômico e social.

\section{Referências}

BARDIN, Laurence. Análise de conteúdo. Lisboa: Edições 70, 2009.

CANÁRIO, Rui. (org.). Formação e situações de trabalho. Porto, Portugal: Porto Editora, 2003.

DAWSON, Bertrand. Informe Dawson sobre al futuro de los servicios médicos y afines, 1920: informe provisional presentado al Ministerio de Salud de la Gran Bretaña en 1920 por el Consejo Consultivo de Servicios Médicos y Afines. Washington, D.C.: Organización Panamericana de la Salud, feb. 1964. 38 p. (OPS Publicación Científica, 93). Disponível em: <www.fundacionaequus.com. ar/biblioteca/infodawson-partel.pdf $>$. Acesso em: 15 jul. 2012.

DUBAR, Claude. Formação, trabalho e identidades profissionais. In: CANÁRIO, Rui (org.). Formação e situações de trabalho. Porto, Portugal: Porto Editora, 2003.

DUBAR, Claude. A socialização: construção das identidades sociais e profissionais. Tradução de Andréa Stahel Monteiro da Silva. São Paulo: Martins Fontes, 2005.

FAVORETO, Cesar A. O. Obstáculos à ampliação da competência dialógica e interpretativa 
da clínica de médicos atuando na atenção primária. In: PINHEIRO, Roseni; MATTOS, Ruben A. (orgs.). Razões públicas para a integralidade em saúde: o cuidado como valor. Rio de Janeiro: Cepesc, 2009. p. 213-229.

FOUCAULT, Michel. Microfísica do poder. Tradução e organização de Roberto Machado. Edição original de 1979. 28. reimp. Rio de Janeiro: Edições Graal, 2010.

FREIDSON, Eliot. Profissão médica: um estudo da sociologia do conhecimento aplicado. 1. ed. Tradução de André de Faria Pereira Neto e Kvieta Brezinova de Morais. São Paulo: Editora Unesp; Porto Alegre: Sindicato dos Médicos, 2009.

HUGHES, Everett C. Men and their work. Edição original. 1958. Disponível em: <www. archive.org/details/mentheirworkOOhugh $>$. Acesso em: 16 out. 2011.

JONES, Anne. H. Literatures and medicine: narrative ethics. Lancet, Londres, n. 349, p. 1243-1246, 1997.

MACHADO, Maria H. Os médicos e sua prática profissional: as metamorfoses de uma profissão. 1996. 245 f. Tese (Doutorado em Ciências Humanas e Sociologia) - Instituto de Pesquisa do Rio de Janeiro, Rio de Janeiro, 1996.

MERHY, Emerson E. Saúde: a cartografia do trabalho vivo. São Paulo: Hucitec, 2007.

MORAES, Ramos. Análise de conteúdo. Revista Educação, Porto Alegre, v. 22, n. 37, p. 732, 1999. Disponível em: <http://cliente.argo. com.br/ mgos/analise_de_conteudo_moraes. html>. Acesso em: 10 maio 2012.

PORTUGAL. Decreto-lei n. 298, de 22 de agosto de 2007. Estabelece o regime jurídico da organização e do funcionamento das unidades de saúde familiar e o regime de incentivos a atribuir a todos os elementos que as constituem. Diário da República. Poder Executivo, Portugal, PT, 22 ago. 2007a. $1^{\text {a }}$ série, n. 161. p. 5.587-5.596.

PORTUGAL. Missão para os Cuidados de Saúde Primários. Cuidados Continuados Integrados nos Cuidados de Saúde Primários: Carteira de Serviços. Ministério da Saúde, Lisboa [Internet]. 2007b. Disponível em: <www.acss.min-saude. pt/Portals/0/Cuidados $\%$ 20Continuados $\% 20$ nos \%20CSP.pdf>. Acesso em: 24 maio 2012.

PORTUGAL. Ministério da Saúde. Cuidados de saúde primários. Agora mais do que nunca. In: MINISTÉRIO DA SAÚDE. A reforma numa página. O que está a mudar nos cuidados de saúde primários em Portugal? Texto 1 da série A reforma de A a Z. 2008. Disponível em: <www. acss.min-saude.pt/Portals/0/01-o_que_esta_ a_mudar_nos_csp_em_portugal.pdf $>$. Acesso em: 5 abr. 2012.

PORTUGAL. Decreto-lei n. 177, de 4 de agosto de 2009. Estabelece o regime de carreira médica especial, bem como os requisitos de habilitação profissional. Diário da República. Poder Executivo, Portugal, PT, 4 ago. 2009. $1^{a}$ série, n. 149, p. 5047-5053. Disponível em: $<$ www.portaldasaude.pt/NR/rdonlyres/ 45AB8EC5-D541-4F0F-BDAB-006F1A1BAC77/ 0/0504705053A.pdf>. Acesso em: 5 abr. 2012.

PORTUGAL. Ministério da Saúde. Nota Técnica $n .^{\circ}$ 1/acss-poph/2011: tipologia de intervenção 3.6 - qualificação dos profissionais da saúde. In: MINISTÉRIO DA SAÚDE. Programa Operacional Potencial Humano. 2011. Disponível em: <www.acss.min-saude.pt/ Portals/0/nota_tecnica_lacss_poph2011.pdf $>$. Acesso em: 5 abr. 2012.

PORTUGAL. Ministério da Saúde. Guião de apoio à preparação de candidaturas a unidades de saúde familiar (USF) - modelo A. Cuidados primários. 2010. Disponível em: $<$ www.acss.min-saude.pt/Portals/0/ guiaoapoiocandidaturasusf_v22102010.pdf $>$. Acesso em: 16 de jun. 2012.

PORTUGAL. Ministério da Saúde. Aperfeiçoamento do modelo retributivo e de incentivos nas unidades de saúde familiar. Grupo Técnico para o Desenvolvimento dos Cuidados de Saúde Primários. Documento de trabalho. Versão de 30 set. 2012. Disponível em: $<$ www.acss.min-saude.pt/Portals/0/ 13-aperfeioamentodomodeloretributivousf 2012.09.30.pdf>. Acesso em: 16 jun. 2012. 
SOUZA, Marize B. et al. Trabalho em equipe na atenção primária: a experiência de Portugal. Revista Panamericana de Salud Pública, Washington, v. 33, n. 3, p. 190-195, mar. 2013.

ZARIFIAN, Philippe. O modelo da competência: trajetória histórica, desafios atuais e propostas. Tradução de Eric Roland e René Heneault. São Paulo: Senac, 2003.
ZARIFIAN, Philippe. Objetivo competência: por uma nova lógica. São Paulo: Atlas, 2011.

Recebido em 20/02/2013

Aprovado em 01/10/2015 